Journal of

Information Systems Engineering

and Business Intelligence

Vol.7, No.2, October 2021

Available online at: http://e-journal.unair.ac.id/index.php/JISEBI

\title{
Technology Adoption in Small-Medium Enterprises based on Technology Acceptance Model: A Critical Review
}

\author{
Adisthy Shabrina Nurqamarani ${ }^{1 *}$ (D), Eddy Soegiarto ${ }^{2)}$, Nurlaeli $^{3)}$ \\ 1)3) Universitas Terbuka, Indonesia \\ Jalan Cabe Raya, Pondok Cabe, Pamulang, Tangerang Selatan \\ 1)adisthy@ecampus.ut.ac.id, ${ }^{3)}$ nurlaeli@ecampus.ut.ac.id \\ 2)Universitas 17 Agustus 1945 Samarinda, Indonesia \\ Jl. Ir. H. Juanda No. 80, Samarinda \\ ${ }^{2)}$ soegiarto@untag-smd.ac.id
}

\begin{abstract}
Background: Technology acceptance model (TAM) has been extensively used to analyse user acceptance of technologies adopted by enterprises at different levels. Moreover, the technology adoption has drawn attention among practitioners and academic communities alike, leading to the development of approaches to understand the concept. However, there is a degree of inconsistency found in previous studies on different types of TAM models used in explaining user acceptance of technologies among small-medium enterprises (SMEs).

Objective: This critical literature review aims to synthesise the technology adoption scholarly studies using TAM. It is expected to aid the identification of the most relevant factors influencing SMEs in adopting technology. Additionally, analysing the variations of TAM developed in previous studies could provide suggested variables specific to the type of technology industry. Methods: An integrated approach was used, and this involves a review of articles on the adoption of technologies in SMEs from 2011 to 2021, retrieved from popular databases using a mixture of keywords such as technology acceptance model (TAM), technology adoption, and technology adoption in SMEs.

Results: An overview of TAM studies on user acceptance of technology in this review covers a wide range of research areas from financial technology to human resource management-related technology. Perceived usefulness and perceived ease of use were discovered to be the most common factors in TAM from the 21 articles reviewed. Meanwhile, some other variables were observed such as context, type of technology and level of user experience.

Conclusion: The review highlights key trends in previous studies on IT adoption in SMEs, which assist researchers and developers in understanding the most relevant factors and suitable TAM models in determining user acceptance in a particular field.
\end{abstract}

Keywords: Technology Acceptance Model, Technology Adoption, Small-medium Enterprises, Critical Review

Article history: Received 30 June 2021, first decision 21 August 2021, accepted 15 September 2021, available online 28 October 2021

\section{INTRODUCTION}

Industrial revolution 4.0 has spurred a radical transformation in traditional industries, which leads to a disruptive leap in industrial processes and fundamental changes in society [1]. This was observed to have been accelerated by the COVID-19 pandemic that changed the way people live globally. Therefore, companies, especially small-medium enterprises (SMEs), need to adopt technological innovation in line with the continuous digital transformation as well as the changes in people's behaviour caused by the pandemic. Studies showed that one of the main causes of the low competitiveness of SMEs' products is the low mastery of technology, especially information technology [2], [3]. Therefore, the role of technology adoption in the economic success and survival of SMEs is a captivating field of research.

SMEs play crucial role in economic growth [3] so it is important to examine their critical success factors. Therefore, it is essential to study the factors determining the success and survival of SMEs, including the user acceptance of the technology adopted by the businesses. Previous studies have discussed several theories and models on technology adoption with the theory of reasoned action and theory of planned behaviour used in developing Technology

\footnotetext{
${ }^{*}$ Corresponding author
} 
acceptance model (TAM) model and diffusion of innovation (DOI) theory, subsequently the technology-organisationenvironment (TOE) model discovered to be the most popular. According to [4], TAM is a solid model to evaluate the determinant factors of financial technology usually applied in MSMEs. TAM is the most powerful model to explain the behaviour towards the acceptance of new technology, especially in relation to the recent digital technology being adopted by different businesses [5].

TAM was used in this research due to its simplicity, popularity in technology acceptance field, and powerful ability to explain the behaviour towards technology acceptance. It has, however, been discovered that this model has several disadvantages such as the production of inconsistent results, development using different variables based on industries or platforms, and the issues regarding its applicability to explain technology adoption. This was observed from the findings of [6] that the model was only able to interpret $40 \%$ of the behaviour of the users towards the system being analysed. Moreover, perceived ease of use in TAM was also reported to be decreasing and inconsistent when the user has experienced the technology [7]. According to [8], TAM has some limitations as indicated by non-normal data, which might cause estimation problems and untrustworthy results. Meanwhile, a small sample size was found to be unreliable as the parameter for the estimation. Therefore, there is a need to include some external variables in the model to ensure a more consistent prediction of technology or system usage [9], [10]. It was also discovered that intrinsic motivations were not addressed in the model. This means it may have limited application in a customer context where the acceptance and use of information technologies are not only focused on performing tasks but also to satisfy emotional needs. It can, therefore, be concluded that there are variations in the TAM variables used in most studies, as well as a growing need to extend or integrate the model in several others.

The background information was used to formulate the research problems, and these include a) the most relevant TAM factors influencing SMEs adoption of technology; and b) the effectiveness of TAM development in analysing technology adoption in SMEs. Therefore, literature needs to be reviewed critically to have a deeper and more comprehensive understanding of TAM. This involved using an integrative approach to examine previous studies related to TAM to explain technology adoption by SMEs. The approach has been confirmed to be effective in improving the understanding of a concept by summarising empirical and theoretical studies [11]. It was used to offer contributions to the field by concisely presenting substantial findings from recent TAM studies which are specifically conducted on SMEs. Therefore, the purpose of this critical review is to identify the most relevant TAM factors or variables influencing SMEs to adopt technology. The findings are expected to provide up-to-date and well-researched references on TAM-related literature particularly within the last 10 years, as well as to recommend appropriate determinant factors for the industries.

\section{LITERATURE REVIEW}

\section{A. Technology Adoption}

Several studies have been previously conducted on the use and adoption of technology in different types and scales of companies [12]-[15] and SMEs were observed to require appropriate solutions and methods to adopt and integrate technology into their business processes[16]. A successful implementation is expected to provide potential benefits for SMEs such as increment in sales, enhancement of profitability, improvement in productivity, reduction in the costs of inventory, procurement and distribution, as well as the enhancement of service quality and strengthened position among competitors. Conversely, unsuccessful application is projected to have a severe impact on SMEs with limited resources[17].

The literature review showed that there are several frameworks often used as references to research technology adoption and these include the innovation adoption model, internal-external factors, TOE, and TAM-each with different strengths and weaknesses. [18] also studied some important theories related to technology adoption such as theory of reason action (TRA), theory of planned behaviour (TPB), theory of interpersonal behaviour, technology acceptance model (TAM), extended technology acceptance model (ETAM), diffusion of innovation theory (DOI), motivational model, perceived characteristics of innovating theory (PCIT), unified theory of acceptance and use of technology (UTAUT), and compatibility UTAUT (C-UTAUT).

Most of these theories were derived from the field of sociology and psychology [19] with the ones mostly used in explaining technology adoption found to include UTAUT, TAM and DOI [18]. "DOI and TAM adopt an unidirectional perspective towards its causal relationship as indicated by the effect of environmental constructs on cognitive beliefs and the subsequent influence on the attitudes and behaviours, as well as its mere focus on beliefs of technology" [20]. According to [21] TRA, TPB, and UTAUT were discovered to be more suitable in explaining technology adoption in an individual context, while TAM and TOE are more perfect for the organisational context. 


\section{B. Technology Acceptance Model (TAM)}

Technology Acceptance Model (TAM) was developed in Davis's Ph.D. thesis to gain in-depth understanding about user acceptance process towards ensuring successful design and implementation of an information system. It was also used to offer a theoretical basis for practical user acceptance tests that enables designers and implementors of the system to evaluate a proposed system [22]. Davis[22] proposed that user acceptance of technology or actual system usage is affected by three major factors, which include attitude towards using the technology or system (ATU), perceived usefulness (PU), and perceived ease of use (PEOU). Moreover, the attitude towards using the system (ATU) is the major determinant factor of the actual system usage, which is affected by both PU and PEOU as indicated in Fig. 1. Meanwhile, PEOU directly influences PU, and they were both hypothesised to be affected by the system design features represented by X1, X2 and X3 in Fig. 1. This phase was defined by [23] as the first phase of TAM development which is known as the introduction period.
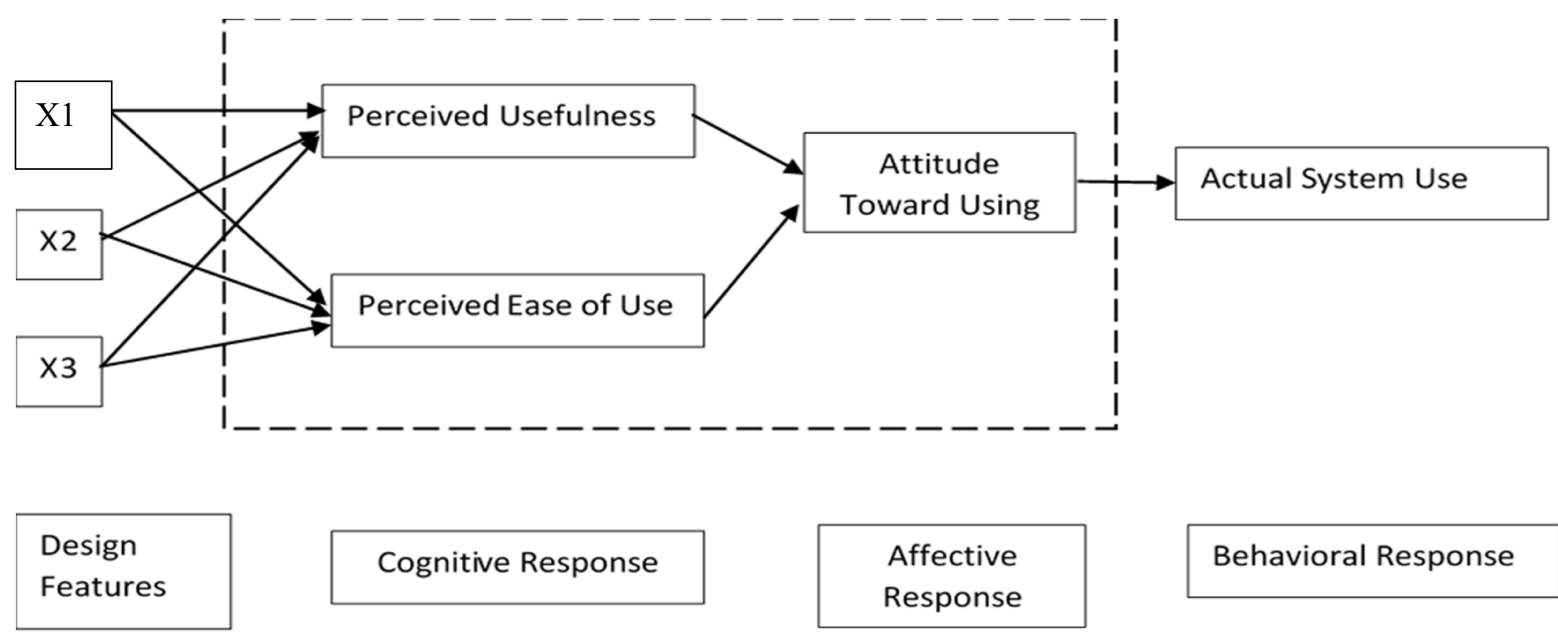

Behavioral Response

Fig. 1 Technology Acceptance Model (TAM) “original version” proposed by [22]

Davis[22] continued experimenting to validate TAM after the introduction period while several other researchers were observed to have attempted to replicate and validate the model in different types of technologies. Therefore, this phase is known as the validation period[23] and Davis was reported to have proposed a modified TAM, which is slightly different from the previous model during this period. Some replication studies were conducted, and the results showed the possibility of some system characteristics influencing the attitude towards using the system directly as indicated in Fig. 2.

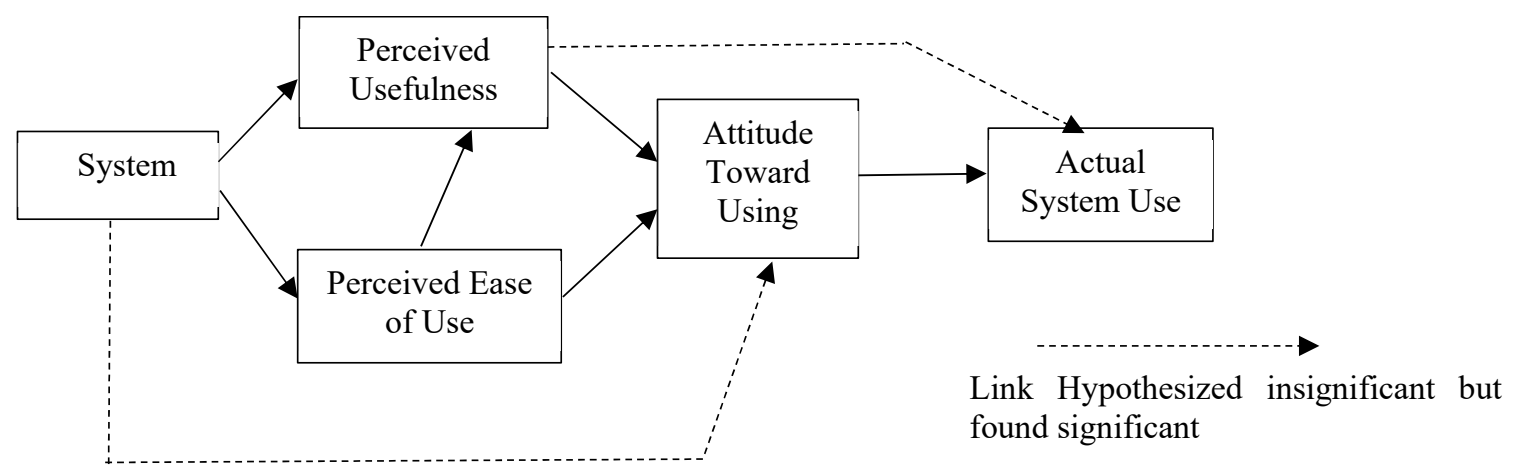

Fig. 2 Causal Diagram of Model Validation Results proposed by [22]

TAM has been applied in different types of technologies, but some scholars believed external variables were not explored by this model, thereby, leading to uncertainty [24]. This led [25] to construct an improved version of technology acceptance model (TAM2) with the addition of voluntariness, subjective norms and image as the new social forces, also four cognitive instrumental processes i.e., job relevance, output quality, result demonstrability, and 
PEOU as indicated in Fig. 3. This improvement model is, therefore, more prevailing in explaining the adoption behaviour [24].

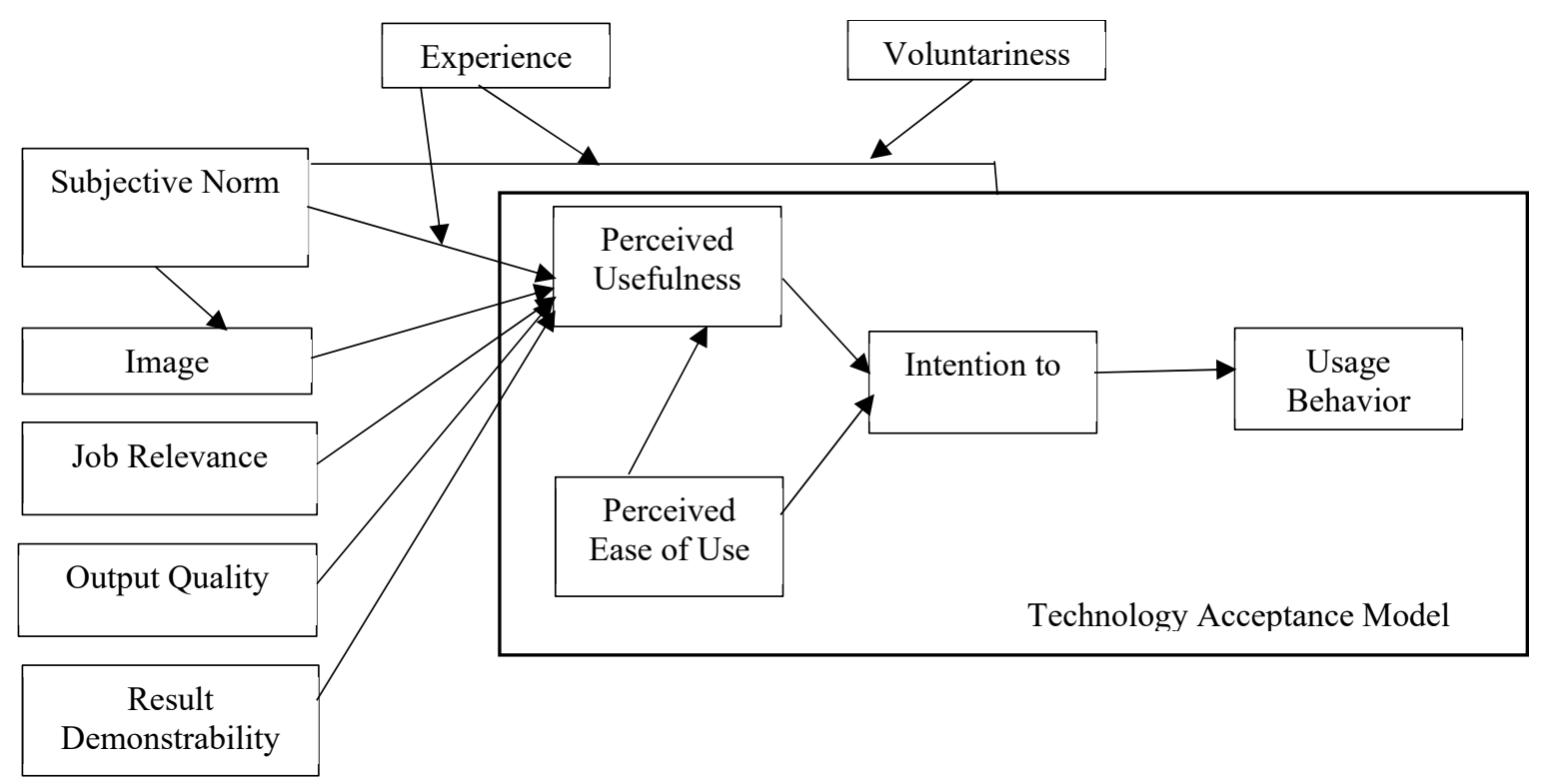

Fig. 3 Extended Model of TAM (TAM2) [22]

TAM was used between 1986-2003 to analyse user acceptance in different types of technologies ranging from communication, general-purpose, office and specialised business systems [23]. Recent studies also showed its application in studying building information modelling [26], digital payment systems [5], [27], financial technology [4] and knowledge management [8]. According to [9], TAM has a robust implication on technology adoption from both theoretical and conceptual perspectives. Meanwhile, [28] reported that it is upfront and offers an adequate explanation for the prediction of diverse user acceptance within a different organisational context and that it also serves as a dominant model to study technological adoption.

\section{Variables of TAM}

\section{Perceived Usefulness (PU)}

According to [22], "perceived usefulness is the degree of consumer belief in technology helpfulness". It was also defined as an important technological factor which explains an individual's behavioural intention to accept and implement the technology [29]. Moreover, [30] explained PU as the degree to which users believe that the use of technology will boost their performance. This means it is possible to measure perceived usefulness based on the technology's ability to improve firm performance, productivity, effectiveness, which will benefit businesses [4].

2. Perceived Ease of Use (PEOU)

This concept was discussed by [22] as the degree to which the use of a system is free from effort. [31] also showed that PEOU is about users' individual assessment of the effort associated with learning and perceived usability of a technology. It is possible to measure this variable based on the lesser difficulty and greater flexibility in using a technology [5]. Moreover, [32] explained PEOU as the extent to which someone believes that using a technology is free from any effort, while [30] showed it is the extent to which the user trusts a technology is free of cognitive effort.

3. Attitude towards using (ATU)

This was explained by [4] as the feeling, either positive or negative, when an individual uses new technologies. This variable can be measured based on the user's feeling and perception of the technology to be a good experience, valuable and favourable [33].

4. External Factors

External factors are those outside the organisation which may influence users in adopting technology, for instance organisational, social, and technical factors affect the awareness of the ease and usefulness of using technology [34] as indicated by Ghorbani et al. as cited in [35].

5. Behavioural Intention (BI) and Actual Usage (U)

According to [36], behavioural intention is the users' willingness to use the technology. It was also defined as the 
seriousness of one's intention to do specific conduct and explained to be a good predictor benchmark of actual use [24], [25]. This concept was also known as the 'intention to use' or the willingness to use the technology. Meanwhile, actual usage was described by [37] as the repeated use of technology over time.

\section{METHODS}

This research reviewed articles on the adoption of technologies in SMEs published from 2011 to 2021. These studies were retrieved from popular databases such as Elsevier, Emerald, Procedia, IEEE, Science Direct and Google Scholar using keywords and a mixture of keywords such as technology acceptance model (TAM), technology adoption, ICT, and SMEs. An integrative or critical review approach was employed but not predominantly developed based on a specific standard [38]. The aim was to critically analyse and observe different pieces of literature with a focus on the main ideas and relationships discussed in them [39]. This integrative approach is, however, the only method which allows the combination of diverse methodologies [38].

The studies on the TAM framework were included to identify relevant variables considered necessary to study the adoption of technology. TAM was selected due to its suitability for organisational context [40] while some other model suits for individual context, simplicity [41], popularity in technology acceptance and powerful ability to explain the behaviour in technology acceptance [5]. Cooper's five-stage integrative review process was used, and this includes formulating the problem, collecting data, evaluating data, analysing data, and interpreting and presenting the results [42]. This was later modified as presented in Fig. 4.

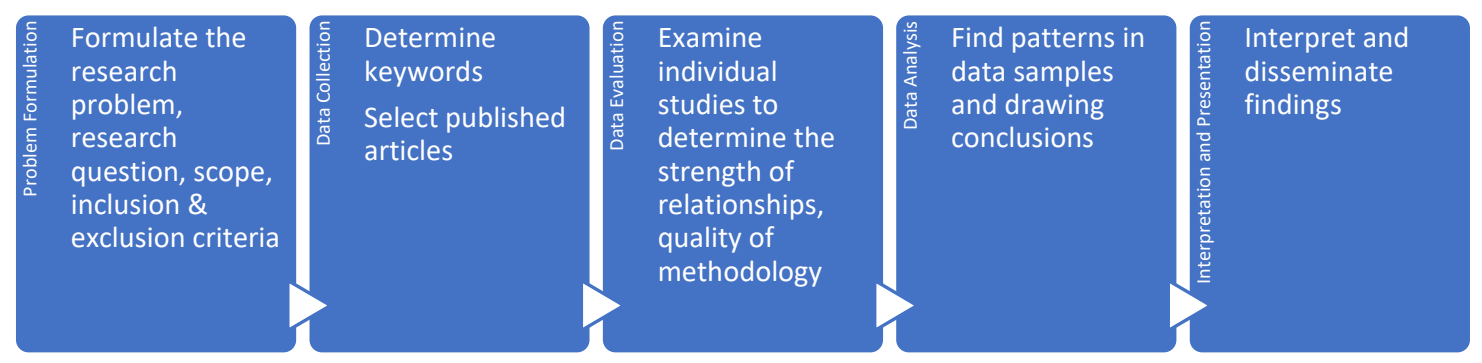

Fig. 4 Integrative approach review process (adopted from [42])

The literature review process started by formulating the research problem and scope which was limited to the studies on the technology adoption by SMEs. This was followed by data collection with studies on technology adoption within the last 10 years (2011-2021) used as the population while some inclusion and exclusion criteria were used to select the samples for this research as indicated in Table 1.

TABLE 1

INCLUSION AND EXCLUSION CRITERIA

\begin{tabular}{lll}
\hline Criteria & Inclusion Criteria & Exclusion Criteria \\
\hline $\begin{array}{l}\text { Language } \\
\text { Theory Used }\end{array}$ & $\begin{array}{l}\text { Written in English } \\
\text { TAM, extended TAM, integration model of TAM and theories } \\
\text { or models }\end{array}$ & $\begin{array}{l}\text { Written in non-English } \\
\text { Studies that do not use TAM }\end{array}$ \\
$\begin{array}{l}\text { Type of } \\
\text { publication }\end{array}$ & Journal articles or conference proceeding & $\begin{array}{l}\text { Books chapters, opinion and preface, master } \\
\text { dissertation } \\
\text { Date }\end{array}$ \\
$\begin{array}{l}\text { Research Design } \\
\text { Empirical study - quantitative approach and/or mixed methods } 2011\end{array}$ & $\begin{array}{l}\text { Beforew paper, empirical study with a qualitative } \\
\text { Revproach }\end{array}$ \\
\hline
\end{tabular}

The second stage was data collection, and this involved searching for determined keywords such as technology acceptance model, small-medium enterprises, and technology adoption within the range of inclusion criteria - mainly from open-access journals and selected published articles. Hundreds of articles were collected based on these keywords and those to be used in the full screening process were shortlisted by reading the abstracts to confirm their compliance with the criteria.

The third stage was data evaluation, and this involved the examination of the quality of methodology, which includes stating the study population clearly, stating well-defined research question and appropriate measurement of outcomes. The strength of relationships and types of technology used by SMEs in each study were also evaluated. 
TAM was also agreed to be used by the authors at this stage mainly due to its benefits previously mentioned. Moreover, the full reading process and evaluation of each paper led to the selection of 21 articles from open access journals and these include nine indexed Scopus journals (Q3:4, Q2:2, Q1;3), 3 Sinta Indexed Journal (S3:1, S4:2), and nine articles from international journal indexed in Google scholar and/or EBSCO.

The fourth stage was data analysis, and this involved the review of TAM development from the original to the extended model, analysis of the significant and insignificant variables of TAM, identification of the most relevant variables in certain types of technology or business operation, as well as the provision of answers to the research questions. The fifth stage was used to interpret and present the findings according to the journal requirement.

TABLE 2

THE SIGNIFICANCE OF THE RELATIONSHIPS IN THE MODEL

\begin{tabular}{lll}
\hline Relationship between variables & \multicolumn{1}{c}{ Significant } \\
\hline Perceived ease of use (PEOU) affects perceived usefulness (PU) & {$[5],[6],[9],[30],[35],[43]-[47]$} & - \\
Perceived ease of use (PEOU) affects Behavioural Intention (BI) & {$[44],[45]$} & {$[8],[37]$} \\
Perceived ease of use (PEOU) affects usage (U) & {$[5],[6],[30],[35],[52]-[54]$} & {$[48]-[50]$} \\
Perceived ease of use (PEOU) affects attitude towards using (ATU) & {$[5],[6],[30],[35],[46],[52]-[54]$} & {$[51]$} \\
Perceived usefulness (PU) affects attitude towards using (ATU) & {$[5],[44],[45],[48],[53],[56]$} & - \\
Perceived usefulness (PU) affects behavioural intention (BI) & {$[37],[57]$} & {$[4],[50]$} \\
Perceived usefulness (PU) affects usage (U) & {$[5],[52],[53]$} & - \\
Attitude towards using (ATU) affects behavioural intention (BI) & {$[4],[35],[46],[54]$} & - \\
Attitude (ATU) affects Usage (U) & {$[48],[49],[56]$} & - \\
Behavioural Intention (BI) affects Usage (U) &
\end{tabular}

\section{RESUlts}

Table 2 shows the significance of the relationships in different technology acceptance models and some gaps were conceptually found on the relationship between PEOU and BI, PU and BI, and PEOU and U. Moreover, [48]-[50] reported there was no significant effect of PEOU on BI. The similarities discovered in these studies are that the technology used is not new, the company has been using different ICT to run its business, as well as the experience of the user. This shows that PEOU has little influence on user intention to adopt a technology when the user is already accustomed to a technology which is related to the one adopted in a company or when the technology is not relatively new.

According to [4], [50] PU has no significant effect on BI. This was possibly associated with the fact that the adopted technology is not new and the familiarisation of the user with different ICTs in running businesses [50]s. It can also be due to the lack of direct effect of PU on BI but the existence of an indirect effect through ATU [4], [58] . Moreover, [51] found that PEOU has no significant effect on U due to the lesser capability of SMEs in terms of knowledge and resources to react fast to any changes requiring adaptation to a system when compared to larger corporation [51].

Some studies that used extended TAM also showed different results. For example, [4]s showed there is no significant effect of external factors on PEOU due to the existence of free access to the instructions or explanation on using the technology without the limitation of education, business age and business size. Meanwhile, [55] studied SMEs retailers and found that the level of education affects PEOU and PU. The reason for the difference in both studies was discovered to be due to the nature of the technology involved. This was observed in the use of TAM in [4] to analyse the adoption of financial technology, specifically financial payment and financial lending, which is possibly less exposed to operational activities of the business and require less complexity compared to social media marketing. Meanwhile, it was used in [55] to evaluate the adoption of social media marketing which requires more time and strategy for its operation.

A different result was also observed in [55] concerning the impact of perceived ease of use on attitudes towards the use of technology as indicated by the absence of any important effect of attitudes on the actual usage of social media marketing. This was possibly associated with the statement that the "retailers believe that learning to use and adopting social media marketing may not be easy" [55] as well as the fact the study was conducted during the pandemic which has a possible influence on the outcomes when compared to a normal reality.

\section{DISCUSSION}

\section{$R Q$ 1: What are the most relevant factors influencing SMEs in adopting technology based on TAM?}

Previous studies showed there are important factors influencing the adoption of technology in SMEs. In line with the perceived usefulness (PU) and perceived ease of use (PEOU) factors used in the original TAM model, most recent studies confirmed the effect of PEOU on PU in SMEs [4], [5], [8], [30], [35], [43]-[47]. The same was also reported 
in the relationship between PEOU and attitude towards using the system (ATU) [5], [6], [30], [35], [52]-[54]; PU and ATU [4], [5], [30], [35], [46], [52], [54]; PU and actual usage (U) [37], [59], ATU and U [4], [35], [46], [54] and behavioural intention (BI) and U [48], [49], [56].

This shows PEOU and PU are the most common TAM factors used in explaining the intention of SMEs to adopt technology. Meanwhile, the contrasting result reported in [7] that the PEOU influence decreased for experienced users was explained by this finding and this is due to the fact that the users in SMEs are relatively new to the technology adopted. Therefore, the impact remains consistent. Moreover, other variables such as ATU the system, BI, and U were observed to have been used by some studies while others do not use them.

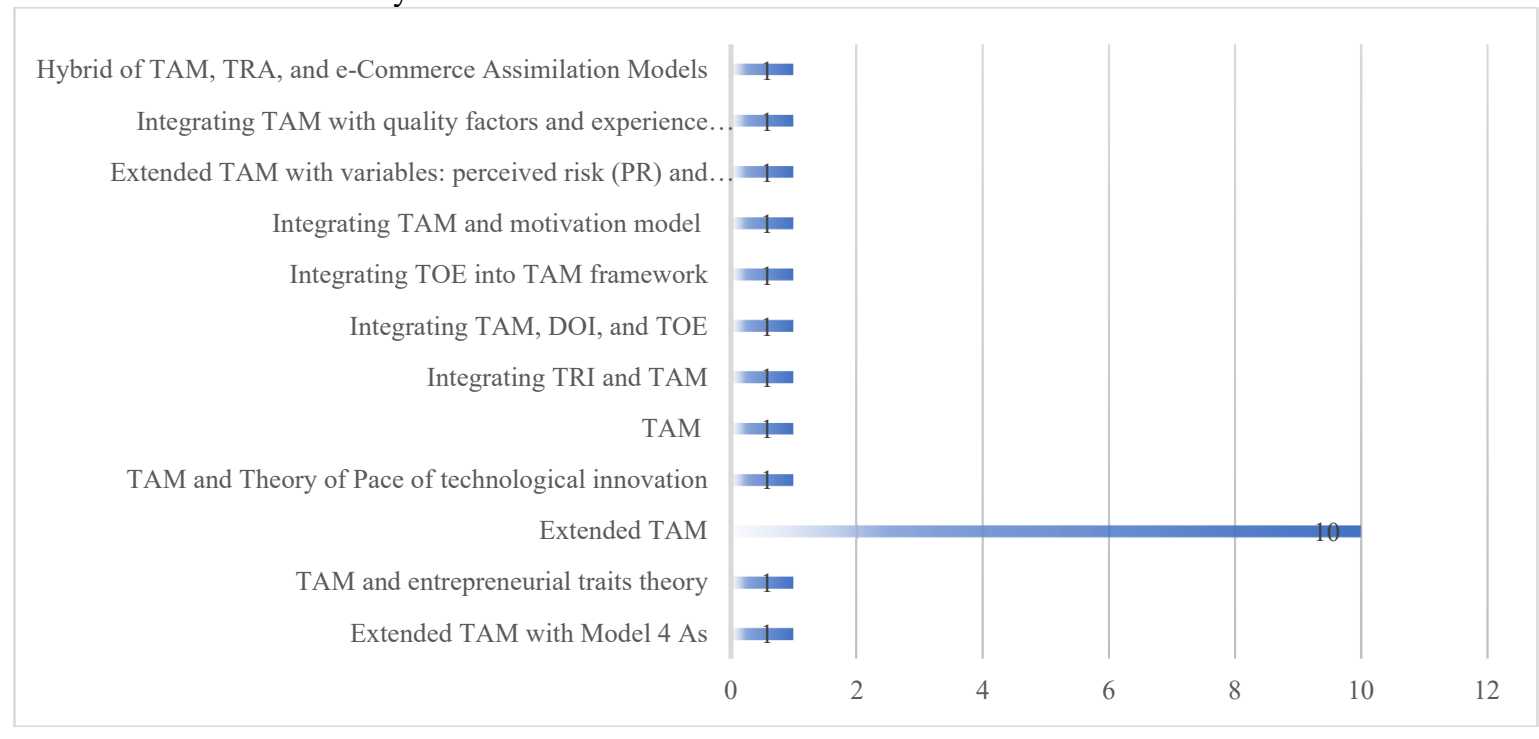

Fig. 5 Type of TAM used to study technology adoption on SMEs

TABLE 3

TYPES OF TAM MODEL (2011-2021)

\begin{tabular}{|c|c|c|}
\hline Authors & Type of Technology & TAM Model \\
\hline$[60]$ & Online Government Credit Program & Extended TAM with Model 4 As \\
\hline [61] & E-Commerce & TAM and entrepreneurial traits theory \\
\hline [55] & Social Media Marketing & Extended TAM with added variable (education) \\
\hline$[52]$ & Financial Technology Application & Extended TAM with added variable (Trust) \\
\hline [56] & Financial technology & Extended TAM \\
\hline [5], [6] & Digital Payment System & Extended TAM with added variable (Trust) \\
\hline [5] & Financial Technology & Extended TAM \\
\hline [43] & Digital Media & Theory of Pace of technological innovation and TAM \\
\hline [37] & Accounting Information System & TAM \\
\hline$[54],[62]$ & Social Media Marketing & Extended TAM \\
\hline [44] & Internet Banking & Extended TAM \\
\hline [9] & $\begin{array}{l}\text { Knowledge Management based web } \\
\text { application }\end{array}$ & Extended TAM \\
\hline$[30]$ & E-HRM Application & Extended TAM \\
\hline [48] & ERP & Integrating TRI and TAM \\
\hline$[50]$ & Cloud Computing & TAM, DOI, and TOE \\
\hline [35] & E-Commerce & Integrating TOE into TAM framework \\
\hline [49] & Internet & TAM and motivation model \\
\hline [59] & Smart Learning & $\begin{array}{l}\text { TAM with added variables perceived risk }(\mathrm{PR}) \text { and organizational innovativeness } \\
(\mathrm{OI}) \text {. }\end{array}$ \\
\hline [46] & Mobile Banking Services & Integrating TAM with quality factors and experience (Extended TAM) \\
\hline [51] & Web-based marketing application & TAM, TRA, and e-Commerce Assimilation Models \\
\hline
\end{tabular}

$R Q$ 2: How effective is the development of TAM in analysing technology adoption in SMEs?

The process of selecting and sorting in this research based on keywords and relevance to the topics led to the selection of 21 academic articles observed to have analysed technology adoption in SMEs based on the TAM from journals and conference proceedings. These articles were written between 2011 and 2021 and different technologies were studied, and these include those applied in sales and marketing (social media marketing, digital media, webbased marketing application, e-commerce and digital payment), human resources development (E-HRM application 
and knowledge management), operations (ERP and information system), Finances (accounting information system, online loan program, and financial technology) as indicated in Fig. 5.

It was also discovered that several variations of TAM were used including the extended TAM as well as the integration of TAM and other models. Meanwhile, the extended version was found to have generally been adapted to several contexts in different countries [5] based on its ability to add moderator variables as against the original model [56]. Most of the TAM-based research which discussed technology adoption in SME also used the extended TAM with the addition of some variables such as trust [5], [52]; external factors [4], [35], [44], [54]; and more specified variables including perceived risk and innovativeness [45], [59]; external pressure [54]; and subjective norms [45].

It was also discovered that some authors used the TAM framework with other models and theories to understand IT adoption [35], [43], [46], [48]-[51], [53] and this is evident in the combination of the TOE and TAM [35], [50], TRA and TAM [48], [51], TAM and IMTA [49], and TAM and TPB [53] as indicated in Fig. 5 and Table 3.

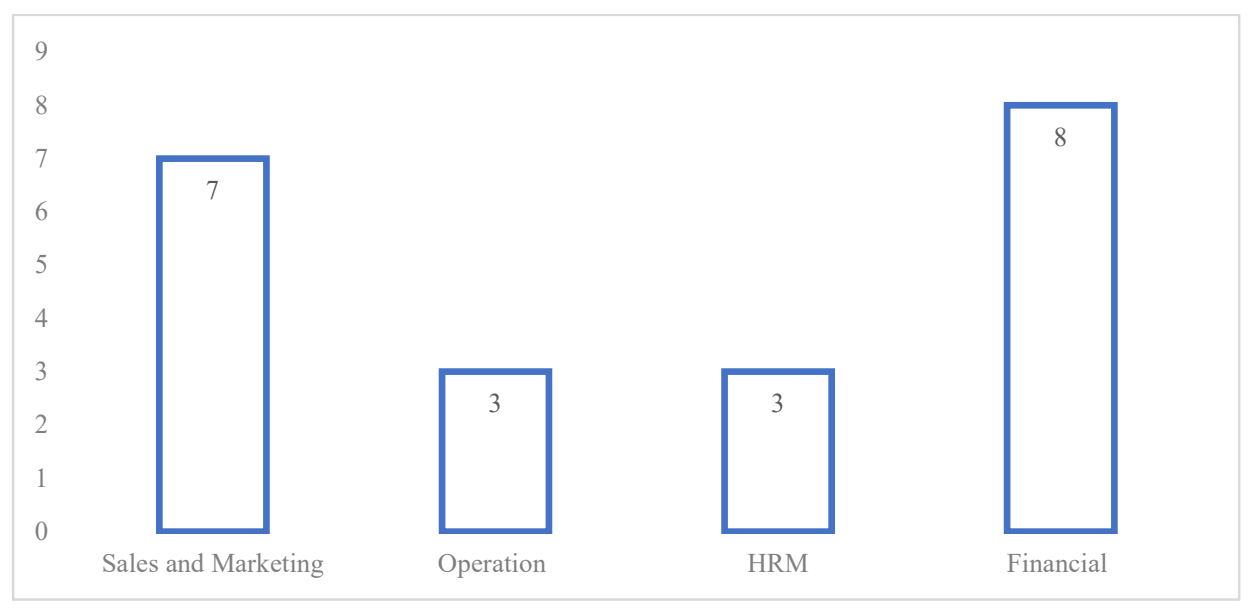

Fig. 6 Technology-related field used by SMEs (2011-2021)

Fig. 6 shows the most common technology studied using TAM in SMEs from the 21 articles reviewed are in the field of finance (eight), followed by sales and marketing (seven), operations (three), and human resources management (three). Moreover, the articles that discussed financial technology showed trust as the most prevalent factor used in the model to analyse the adoption of the technology in SMEs [5], [52]. This variable is considered important due to the risk perceived by users regarding the payment systems through the internet or digital technology, especially in developing countries. [63] also added brand and service trust variables into the model for financial technology while some other studies were observed to vary some external factors such as personal innovativeness, regulatory support, readiness to use technology, financial support, competitive pressures, quality; and Model 4As which include availability, awareness, affordability and acceptability considered to have the ability of explaining the use of microfinance credit [60].

Subjective norms are perceptions of certain behaviour an individual is or does not expect to perform which is very subjective according to each person [64]. This variable was reported to have the ability to influence community members to use online loan programs [60]. Meanwhile, another study also used factors of quality such as quality of the system, information and service to analyse the adoption of mobile banking services based on their influence on the perceived ease of use which indirectly affects the use of technology [46].

Technologies related to sales and marketing include social media marketing, digital media, e-commerce and webbased marketing application and social media marketing was found to be the growing trend and perceived to be an efficient channel for business communications [62]. It is also critical to point out that the variables usually used in sales and marketing-related technology vary based on educational background [55], the pace of technological innovation, technology anxiety [43], manager innovativeness, pressure, barrier [65], external support and pressure, time constraint, technical knowledge [54], security and privacy, attitude and knowledge, government support, product fit, and technical knowledge availability [51]. Moreover, the studies conducted on the technologies related to human resource management mostly used the extended model with variables adapted from [25] as indicated in Fig. 3 while those related to the general business operation were observed to have integrated other theories to cater for the weaknesses of the original model as well as different needs and contexts. For instance, [48]s integrated TRI and TAM to analyse ERP adoption, [50] used a joined model of technology acceptance model (TAM), diffusion of innovation (DOI), and technology-organisation-environment (TOE) to analyse cloud computing adoption, and [49] combined 
TAM and motivation model with the integrated model of technology acceptance (IMTA). Some of the key points associated with the application of TAM in SMEs are presented in the following table.

TABLE 4

CHARACTERISTICS OF TAM APPLICATION IN SME (2011-2021)

\begin{tabular}{|c|c|}
\hline \multicolumn{2}{|c|}{ Characteristics of TAM application in small-medium enterprises } \\
\hline Variables & Depend on the type of technology \\
\hline $\begin{array}{l}\text { Variables of TAM in } \\
\text { sales and marketing } \\
\text { technology }\end{array}$ & $\begin{array}{l}\text { Need of achievement, risk-taking propensity, perceived usefulness (PU), perceived ease of use (PEOU), behavioural } \\
\text { intention (BI), education, attitude towards using (ATU), pace of technological innovation, technological anxiety, } \\
\text { adoption (U), manager innovativeness, pressure, barrier, managerial support, pressure from competitors, pressure from } \\
\text { customers, time constraints, technical knowledge, external factors (technology barriers, organisation barriers, } \\
\text { environmental barriers), security and privacy, entrepreneur's attitude and knowledge, product fit, technical knowledge } \\
\text { availability, and government support. }\end{array}$ \\
\hline $\begin{array}{l}\text { Variables of TAM in } \\
\text { financial technology }\end{array}$ & $\begin{array}{l}\text { Perceived ease of use (PEOU), perceived usefulness (PU), attitude (ATU), subjective norms, availability, awareness, } \\
\text { acceptability, trust, affordability, and behavioural intention (BI), brand and service trust (T), compatibility, perceived } \\
\text { enjoyment, personal innovativeness, financial reports (U), end-user satisfaction, ICT readiness, regulatory support, } \\
\text { financial institution support, and competitive pressure, quality (the quality of information and quality of service and } \\
\text { the quality of the system), and external factors. }\end{array}$ \\
\hline Variables of TAM in & Optimism, innovativeness, discomfort, security, perceived usefulness (PU), perceived ease of use (PEOU), intention to \\
\hline $\begin{array}{l}\text { Operation } \quad \text { (whole } \\
\text { business) }\end{array}$ & $\begin{array}{l}\text { use }(\mathrm{BI}) \text {, actual use }(\mathrm{U}) \text {, relative advantage, compatibility, security concern, technology readiness, top management } \\
\text { support, firm size, external pressure, service provider support, intrinsic motivation, and extrinsic motivation. }\end{array}$ \\
\hline $\begin{array}{l}\text { Variables of TAM in } \\
\text { HRM }\end{array}$ & $\begin{array}{l}\text { Perceived ease of use (PEOU), voluntaries use (VU), perceived usefulness (PU), usage (U), subjective norms, } \\
\text { behavioural intention, user satisfaction and perceived abilities, perceived risk (PR), organisational innovativeness (OI) }\end{array}$ \\
\hline Most common & Perceived ease of use (PEOU) and perceived usefulness (PU) in all types of technology. \\
\hline factors used in TAM & *Trust is a relevant factor which determines technology adoption in financial technology \\
\hline Types of TAM used & Most cases use extended TAM and/or integrated TAM with other theories or models \\
\hline $\begin{array}{l}\text { Relationship } \\
\text { between variables }\end{array}$ & $\begin{array}{l}\text { The significance of the relationship between perceived ease of use (PEOU), perceived usefulness (PU), and behavioural } \\
\text { intention (BI) mainly depends on the novelty of the technology and the level of user experience to similar technology. }\end{array}$ \\
\hline Flexibility & High, can be integrated with other theories and model \\
\hline
\end{tabular}

\section{CONCLUSIONS}

Adoption of technology provides numerous benefits to SMEs by increasing their productivity and reducing their cost of production. There are, however, some challenges impeding technology adoption by these SMEs. Therefore, this research critically reviewed previous studies on IT adoption in these enterprises to enable researchers and developers to understand the most relevant factors and suitable TAM models to determine users' acceptance of technology in a particular field. It also covers the development of TAM from its original to the extended model and the subsequent application in studying technology adoption. Moreover, the set of variables presented have been applied to different technologies in several industries within the scope of SMEs and perceived ease of use and perceived usefulness were discovered to be the most common factors as indicated by the 21 articles reviewed. Meanwhile, several other variables such as trust, model 4As, external factors for financial technology, entrepreneurial traits, education, external factors for sales and marketing technology, and a combination of models and theories for human resources management and operations-related technology have been added to the extended version.

The value added by this research is the determination of the most common variables used based on the type of technology related to certain fields and this is expected to enable the development of an appropriate framework to study technology adoption in a specific field of technology for SMEs in the future research. However, several limitations were discovered, and these include the restriction of the scope to only SMEs, the inability to review articles from high reputable journals due to limited access, and the adoption of an integrative approach which may lack transparency regarding the reviewing process. Therefore, it is recommended that future research discuss and compare several frameworks in explaining technology adoption in firms and to add more articles from high reputable journals or use a different approach like systematic literature review or meta-analysis.

Author Contributions: Adisthy Shabrina Nurqamarani: conceptualization (formulate the idea and research aims), designing the methodology, conducting data collection and analysis, interpreting data, writing the original draft, review, and editing, Eddy Soegiarto: formulation of research problem and financial support, Nurlaeli: supervision and validation.

Funding: This research received no specific grant from any funding agency.

Conflicts of Interest: The authors declare no conflict of interest. 


\section{REFERENCES}

[1] A. Petrillo, R. Cioffi, and F. De Felice, Digital Transformation in Smart Manufacturing. IntechOpen, 2018.

[2] B. R. Payu, "Pemetaan UKM di Kota Gorontalo Berdasarkan Pola dan Tingkat Penggunaan Teknologi Informasi." Universitas Negeri Gorontalo, 2013.

[3] T. A. Lubis and Junaidi Junaidi, "Pemanfaatan teknologi informasi pada usaha mikro kecil dan menengah di Kota Jambi," J. Perspekt. Pembiayaan dan Pembang. Drh., vol. 3, no. 3, pp. 163-174, 2016.

[4] P. Purnamasari, irena paramita Pramono, R. Haryatiningsih, shahifol arbi Ismail, and R. Shafie, "Technology Acceptance Model of Financial Technology in Micro, Small, and Medium Enterprises (MSME) in Indonesia,” J. Asian Financ. Econ. Bus., vol. 7, no. 10, pp. 981-988, Oct. 2020, doi: 10.13106/jafeb.2020.vol7.no10.981.

[5] M. Najib and F. Fahma, "Investigating the adoption of digital payment system through an extended technology acceptance model: An insight from the Indonesian small and medium enterprises," Int. J. Adv. Sci. Eng. Inf. Technol., vol. 10, no. 4, pp. 1702-1708, 2020.

[6] Y. J. Lim, A. Osman, S. N. Salahuddin, A. R. Romle, and S. Abdullah, "Factors Influencing Online Shopping Behavior: The Mediating Role of Purchase Intention," Procedia Econ. Financ., vol. 35, pp. 401-410, 2016, doi: 10.1016/S2212-5671(16)00050-2.

[7] T. Al-maghrabi, C. Dennis, and S. Vaux Halliday, "Antecedents of continuance intentions towards e-shopping: the case of Saudi Arabia," J. Enterp. Inf. Manag., vol. 24, no. 1, pp. 85-111, Jan. 2011, doi: 10.1108/17410391111097447.

[8] J. J. Siregar, R. A. A. Wardaya Puspokusumo, and A. Rahayu, "Analysis of Affecting Factors Technology Acceptance Model in The Application Of Knowledge Management for Small Medium Enterprises in Industry Creative,” Procedia Comput. Sci., vol. 116, pp. 500 508, 2017, doi: 10.1016/j.procs.2017.10.075.

[9] H. Gangwar, H. Date, and A. D. Raoot, "Review on IT adoption: insights from recent technologies," J. Enterp. Inf. Manag., vol. 27, no. 4, pp. 488-502, Jul. 2014, doi: 10.1108/JEIM-08-2012-0047.

[10] H. Taherdoost, "Development of an adoption model to assess user acceptance of e-service technology: E-Service Technology Acceptance Model," Behav. Inf. Technol., vol. 37, no. 2, pp. 173-197, Feb. 2018, doi: 10.1080/0144929X.2018.1427793.

[11] M. H. Oermann and J. C. Hays, Writing for Publication in Nursing. New York, NY: Springer Publishing Company, 2018.

[12] Z. Arifin, A. Fontana, and S. H. Wijanto, "The determinant factors of technology adoption for improving firm's performance: An empirical research of Indonesia's electricity company,” Gadjah Mada Int. J. Bus., vol. 18, no. 3, pp. 237-261, 2016.

[13] F. Budiono, S. Lau, and W. J. Tibben, "The Investigation of E-Marketplace Adoption by Small Medium Enterprises Using IndividualTechnology-Organization-Environment (ITOE) Framework: A Case Study in Yogyakarta Province Indonesia," Pacific Asia J. Assoc. Inf. Syst., vol. 12, no. 4, p. 3, 2020, doi: 10.17705/1 pais. 12403.

[14] J. L. Chong and K. Olesen, "A Technology-Organization-Environment Perspective on Eco-effectiveness: A Meta-analysis," Australas. J. Inf. Syst., vol. 21, Mar. 2017, doi: 10.3127/ajis.v21i0.1441.

[15] A. D. Ramdansyah and H. E. R. Taufik, "Adoption model of e-commerce from smes perspective in developing country evidence--case study for Indonesia." University of Piraeus. International Strategic Management Association, 2017.

[16] Y. Y. Maryeni, R. Govindaraju, B. Prihartono, and I. Sudirman, "Technological and organizational factors influencing the e-commerce adoption by Indonesian SMEs," in 2012 IEEE International Conference on Management of Innovation \& Technology (ICMIT), Jun. 2012, pp. 436-441, doi: 10.1109/ICMIT.2012.6225845.

[17] S. Chong, "Success in electronic commerce implementation," J. Enterp. Inf. Manag., vol. 21, no. 5, pp. 468-492, Sep. 2008, doi: $10.1108 / 17410390810904247$.

[18] H. Taherdoost, "A review of technology acceptance and adoption models and theories," Procedia Manuf., vol. 22, pp. 960-967, 2018, doi: 10.1016/j.promfg.2018.03.137

[19] M.-P. Gagnon, E. Sánchez, and J. M. Pons, "From recommendation to action: psychosocial factors influencing physician intention to use Health Technology Assessment (HTA) recommendations," Implement. Sci., vol. 1, no. 1, p. 8, Dec. 2006, doi: 10.1186/1748-5908-1-8.

[20] K. D. Carillo, "Social cognitive theory in is research--literature review, criticism, and research agenda," in International Conference on Information systems, Technology and management, 2010, pp. 20-31.

[21] T. Oliveira and M. F. Martins, "Information technology adoption models at firm level: review of literature," in The European Conference on Information Systems Management, 2010, p. 312.

[22] F. D. Davis, "A technology acceptance model for empirically testing new end-user information systems: Theory and results," Massachusetts Institute of Technology, 1985.

[23] Y. Lee, K. A. Kozar, and K. R. T. Larsen, "The Technology Acceptance Model: Past, Present, and Future,” Commun. Assoc. Inf. Syst., vol. 12, no. 1, p. 50, 2003, doi: 10.17705/1CAIS.01250.

[24] L. Zhong, X. Zhang, J. Rong, H. K. Chan, J. Xiao, and H. Kong, "Construction and empirical research on acceptance model of service robots applied in hotel industry," Ind. Manag. Data Syst., vol. 121, no. 6, pp. 1325-1352, Jun. 2021, doi: 10.1108/IMDS-11-2019-0603.

[25] V. Venkatesh and F. D. Davis, "A Theoretical Extension of the Technology Acceptance Model: Four Longitudinal Field Studies," Manage. Sci., vol. 46, no. 2, pp. 186-204, Feb. 2000, doi: 10.1287/mnsc.46.2.186.11926.

[26] M. Bastan, M. Zarei, R. Tavakkoli-Moghaddam, and H. S. G., "A new technology acceptance model: a mixed-method of grounded theory and system dynamics," Kybernetes, vol. ahead-of-p, no. ahead-of-print, Feb. 2021, doi: 10.1108/K-03-2020-0127.

[27] C. K. Lok, "Adoption of Smart Card-Based E-Payment System for Retailing in Hong Kong Using an Extended Technology Acceptance Model," Emerald Group Publishing Limited, 2015, pp. 255-466.

[28] A. S. Carr, M. Zhang, I. Klopping, and H. Min, "RFID Technology: Implications for Healthcare Organizations," Am. J. Bus., vol. 25, no. 2, pp. 25-40, Oct. 2010, doi: 10.1108/19355181201000008.

[29] W. R. King and J. He, “A meta-analysis of the technology acceptance model,” Inf. Manag., vol. 43, no. 6, pp. 740-755, Sep. 2006, doi: 10.1016/j.im.2006.05.003.

[30] W. A. Nasser and K. Prabhakar, "Technology acceptance model (TAM): Design of employee engagement practices with special evidence from micro small and medium enterprises (MSME) in Tamilnadu," Int. J. Manag. I\& Soc. Sci., vol. 5, no. 1, pp. 55-62, 2017.

[31] M.-C. Lee, "Factors influencing the adoption of internet banking: An integration of TAM and TPB with perceived risk and perceived benefit," Electron. Commer. Res. Appl., vol. 8, no. 3, pp. 130-141, May 2009, doi: 10.1016/j.elerap.2008.11.006.

[32] R. Nunkoo, T. D. Juwaheer, and T. Rambhunjun, "Applying the extended technology acceptance model to understand online purchase behavior of travelers," in Proceedings of 21st international business research conference, 2013, pp. 10-11.

[33] F. Weng, R.-J. Yang, H.-J. Ho, and H.-M. Su, "A TAM-Based Study of the Attitude towards Use Intention of Multimedia among School Teachers," Appl. Syst. Innov., vol. 1, no. 3, p. 36, Sep. 2018, doi: 10.3390/asi1030036. 
[34] K. C. Mpofu, D. Milne, and L. Watkins-Mathys, "ICT Adoption and Development of E-business among SMEs in South Africa," Buckinghamshire New University, 2013.

[35] M. Esmaeilpour, S. Y. Hoseini, and Y. Jafarpour, “An empirical analysis of the adoption barriers of e-commerce in small and medium sized enterprises (SMEs) with implementation of technology acceptance model," J. Internet Bank. Commer., vol. 21, no. 2, pp. 1-24, 2016.

[36] S. Bamberg, I. Ajzen, and P. Schmidt, "Choice of Travel Mode in the Theory of Planned Behavior: The Roles of Past Behavior, Habit, and Reasoned Action," Basic Appl. Soc. Psych., vol. 25, no. 3, pp. 175-187, Sep. 2003, doi: 10.1207/S15324834BASP2503_01.

[37] M. Andarwati, D. Zuhroh, and F. Amrullah, "End User Satisfaction of Accounting Information System (AIS) Mobile Based for Small Medium Enterprises (SMEs): Actual Usage and TAM Approach,” J. Dev. Res., vol. 3, no. 2, pp. 37-42, 2019.

[38] R. Whittemore and K. Knafl, "The integrative review: updated methodology," J. Adv. Nurs., vol. 52, no. 5, pp. 546-553, Dec. 2005, doi: 10.1111/j.1365-2648.2005.03621.x.

[39] H. Snyder, "Literature review as a research methodology: An overview and guidelines," J. Bus. Res., vol. 104, pp. 333-339, Nov. 2019, doi: 10.1016/j.jbusres.2019.07.039.

[40] F. Cruz-Jesus, A. Pinheiro, and T. Oliveira, "Understanding CRM adoption stages: empirical analysis building on the TOE framework," Comput. Ind., vol. 109, pp. 1-13, Aug. 2019, doi: 10.1016/j.compind.2019.03.007.

[41] P. Ajibade, "Technology acceptance model limitations and criticisms: Exploring the practical applications and use in technology-related studies, mixed-method, and qualitative researches," Libr. Philos. Pract., 2018.

[42] C. L. Russell, “An Overview of the Integrative Research Review,” Prog. Transplant., vol. 15, no. 1, pp. 8-13, Mar. 2005, doi: $10.1177 / 152692480501500102$.

[43] M. A. Camilleri, "The SMEs' technology acceptance of digital media for stakeholder engagement," J. Small Bus. Enterp. Dev., vol. 26, no. 4, pp. 504-521, Aug. 2019, doi: 10.1108/JSBED-02-2018-0042.

[44] R. Rokhim, P. Wulandari, and I. Mayasari, "Small medium enterprises technology acceptance model: A conceptual review," Int. J. Bus. Soc., vol. 19, no. S4, pp. 689-699, 2018.

[45] H. Yanto, B. D. Handayani, B. Solikhah, and J. M. Mula, "The Behavior of Indonesian SMEs in Accepting Financial Accounting Standards without Public Accountability.," Int. J. Bus. I\& Manag. Sci., vol. 6, no. 1, 2016.

[46] M. J. Alsamydai, “Adaptation of the technology acceptance model (TAM) to the use of mobile banking services," Int. Rev. Manag. Bus. Res., vol. 3, no. 4, p. 2039, 2014.

[47] O. Al-Hujran, E. M. Al-Lozi, M. M. Al-Debei, and M. Maqableh, "Challenges of Cloud Computing Adoption From the TOE Framework Perspective," Int. J. E-bus. Res., vol. 14, no. 3, pp. 77-94, Jul. 2018, doi: 10.4018/IJEBR.2018070105.

[48] N. Larasati and P. I. Santosa, "Technology readiness and technology acceptance model in new technology implementation process in low technology SMEs," Int. J. Innov. Manag. Technol., vol. 8, no. 2, p. 113, 2017.

[49] M. C. J. Caniëls, H. K. L. Lenaerts, and C. J. Gelderman, "Explaining the internet usage of SMEs: The impact of market orientation, behavioural norms, motivation and technology acceptance," Internet Res., vol. 25, no. 3, pp. 358-377, Jun. 2015, doi: 10.1108/IntR-122013-0266.

[50] D. Kumar, H. V. Samalia, and P. Verma, "Factors Influencing Cloud Computing Adoption by Small and Medium-Sized Enterprises (SMEs) In India," Pacific Asia J. Assoc. Inf. Syst., vol. 9, no. 3, pp. 25-48, 2017, doi: 10.17705/1pais.09302.

[51] A. Omar, T. Ramayah, L. B. Lin, O. Mohamad, and M. Marimuthu, "Determining factors for the usage of web-based marketing applications by small and medium enterprises (SMEs) in Malaysia," J. Mark. Dev. Compet., vol. 5, no. 2, pp. 70-86, 2011.

[52] C. Sa'diyah, “Analysis Of Factors Affecting Adoption Of Financial Technology Application,” Sentralisasi, vol. 10, no. 1, pp. 57-70, 2021.

[53] A. Sarlan, R. Ahmad, W. F. W. Ahmad, and D. D. Dominic, "A study of SME private healthcare personnel acceptance of Clinic Information System in Malaysia,” Int. J. Bus. Inf. Syst., vol. 14, no. 2, p. 238, 2013, doi: 10.1504/IJBIS.2013.056141.

[54] R. Matikiti, M. Mpinganjira, and M. Roberts-Lombard, "Application of the Technology Acceptance Model and the TechnologyOrganisation-Environment Model to examine social media marketing use in the South African tourism industry," SA J. Inf. Manag., vol. 20, no. 1, pp. 1-12, Apr. 2018, doi: 10.4102/sajim.v20i1.790.

[55] M. T. Salam, H. Imtiaz, and M. Burhan, "The perceptions of SME retailers towards the usage of social media marketing amid COVID19 crisis," J. Entrep. Emerg. Econ., vol. 13, no. 4, pp. 588-605, Sep. 2021, doi: 10.1108/JEEE-07-2020-0274.

[56] W. Ramadhanti, K. Kurniawan, M. Mukhrodin, and S. M. Setyawati, "Extended tam test on indonesian SMEs' fintech users \& its financial reports," SAR (Soedirman Account. Rev. J. Account. Bus., vol. 5, no. 1, p. 83, Aug. 2020, doi: 10.20884/1.sar.2020.5.1.3193.

[57] E. T. Efraim Turban, D. K. J. K. King Jae Kyu Lee, and others, Electronic commerce a managerial and social networks perspective. New York: Springer, 2015.

[58] R. Septiani, P. W. Handayani, and F. Azzahro, "Factors that Affecting Behavioral Intention in Online Transportation Service: Case study of GO-JEK," Procedia Comput. Sci., vol. 124, pp. 504-512, 2017, doi: 10.1016/j.procs.2017.12.183.

[59] J. Lee, M. Choi, and H. Lee, "Factors affecting smart learning adoption in workplaces: comparing large enterprises and SMEs," Inf. Technol. Manag., vol. 16, no. 4, pp. 291-302, Dec. 2015, doi: 10.1007/s10799-014-0201-5.

[60] R. Rokhim, I. Mayasari, and P. Wulandari, “The factors that influence small and medium enterprises' intention to adopt the government credit program," J. Res. Mark. Entrep., vol. 23, no. 1, pp. 175-194, Jul. 2021, doi: 10.1108/JRME-01-2020-0013.

[61] M. N. H. Bin Yusoff, F. A. Zainol, R. Hafifi Ridzuan, M. Ismail, and A. Afthanorhan, "Psychological Traits and Intention to Use ECommerce among Rural Micro-Entrepreneurs in Malaysia," J. Theor. Appl. Electron. Commer. Res., vol. 16, no. 5, pp. 1827-1843, Jun. 2021, doi: 10.3390/jtaer16050102.

[62] M. I. Dahnil, K. M. Marzuki, J. Langgat, and N. F. Fabeil, "Factors Influencing SMEs Adoption of Social Media Marketing," Procedia - Soc. Behav. Sci., vol. 148, pp. 119-126, Aug. 2014, doi: 10.1016/j.sbspro.2014.07.025.

[63] L.-M. Chuang, C.-C. Liu, and H.-K. Kao, "The adoption of fintech service: TAM perspective," Int. J. Manag. Adm. Sci., vol. 3, no. 7 , pp. 1-15, 2016.

[64] N. Huda, N. Rini, Y. Mardoni, and P. Putra, "The analysis of attitudes, subjective norms, and behavioral control on muzakki's intention to pay zakah,” Int. J. Bus. Soc. Sci., vol. 3, no. 22, pp. 271-279, 2012.

[65] D. Sugandini, M. I. Effendi, Y. Istanto, R. Arundati, and E. D. Rahmawati, "Technology-Organization-Environment Model and Technology Acceptance Model in Adoption of Social Media Marketing on SMEs Tourism," J. Environ. Manag. I\& Tour., vol. 10, no. 4 (36), pp. 878-885, 2019 